\title{
Differentiation between localized and generalized airway obstruction
}

\author{
BO G. SIMONSSON ANDR.MALMBERG \\ From the Pulmonary Physiological Laboratory, University Lung Clinic, Renströmska Sjukhuset, Göteborg, \\ Sweden
}

Before operating on patients with lung tumours, we often need to know whether their air flow obstruction is caused entirely by the local tumour or whether there is generalized obstruction from bronchitis or emphysema as well. In the former case, the post-operative period may be expected to be uneventful, since the cause of the obstruction, the tumour, is removed. In the latter, special measures have to be taken to meet with postoperative breathing difficulties.

This paper presents a study of dynamic ventilatory capacities and distribution of air in the lungs, measured with single-breath tests in patients with bronchial and tracheal tumours. The size of the tumour was observed by bronchoscopy and radiography; several specimens were also examined after resection.

\section{MATERIAL}

Nineteen patients, all with bronchial or tracheal tumours, were divided into two groups. Group 1 comprised patients without persisting signs or history of bronchitis or airways obstruction, namely, (a) two patients with tracheal stenosis; and (b) six men and two women, aged 18 to 69 years, with tumours in the central airways, usually the main bronchus (Table I). Group 2 consisted of patients with a history of chronic non-specific broncho-pulmonary disease, many of whom had smoked for several years and were breathless. There were nine men aged 37 to 77 years (Table II).

We thought at bronchoscopy that air could pass the tumour in all these patients.

\section{METHOD AND CLASSIFICATION}

The spirometry was performed with low flowresistance spirometers built according to Bernstein,
D'Silva, and Mendel (1952). The volumes obtained were compared with normal values from this $\mathbb{D}$ laboratory (Berglund, Birath, Bjure, Grimby, $\frac{\mathbb{\Phi}}{\Phi}$ Kjellmer, Sandqvist, and Söderholm, 1963). The $\frac{\mathbb{D}}{3}$ patients were considered obstructive when the F.E.V $\cdot_{1.0}{ }^{1}$ and F.E.V.\% were less than the normal ${ }^{-}$ predicted minus two standard deviations (S.D.). If the F.E.V $\cdot_{1.0}$ and the F.V.C. were less than $\ddagger$ normal minus two S.D. but the F.E.V. $\%$ was normal, the subjects were classified as restrictive.

The distribution of air in the lungs was evaluated with four to five single-breath $\mathrm{N}_{2}$-curves, in which the 'alveolar' nitrogen gradient was $\frac{\mathbb{\Phi}}{\varnothing}$ obtained with a method already described in detail (Kjellmer, Sandqvist, and Berglund, 1959). 의 The result was considered pathological when the mean $\mathrm{N}_{2}$-gradient between the expired volumes750 and $1,250 \mathrm{ml}$. was equal to or higher than the upper $95 \%$ confidence limit in normal materialo from this laboratory (Sandqvist and Kjellmer, $\underset{\times}{\stackrel{D}{ٍ}}$ 1960).

\section{RESULTS}

Both subjects with tracheal stenosis were severely윽 obstructive on expiration (Table I). In subject J. J., , figures obtained with forced inspiration showed an even more severe inspiratory obstruction, the N F.E.V./F.I.V. ratio being 1.41 . In spite of this extensive obstruction, the single-breath $\mathrm{N}_{2}$ was normal.

In the eight patients in group $1 \mathrm{~b}$, six of whom had narrowing of one main bronchus, six patientse were obstructive and two were restrictive (Table I). The $\mathrm{N}_{2}$-gradient was below the upper $95 \% \stackrel{\text { ? }}{?}$ confidence limit in all. The difference between the 0 pairs of measured mean values and the individual predicted upper limits was significant $(\mathbf{P}<0 \cdot 001)$.

1 Nomenclature according to Gandevia and Hugh-Jones (1957) 
TABLE I

VENTILATORY CAPACITIES AND GAS DISTRIBUTION IN THE LUNGS OF PATIENTS WITH BRONCHIAL TUMOURS BUT WITHOUT CHRONIC RESPIRATORY DISEASE

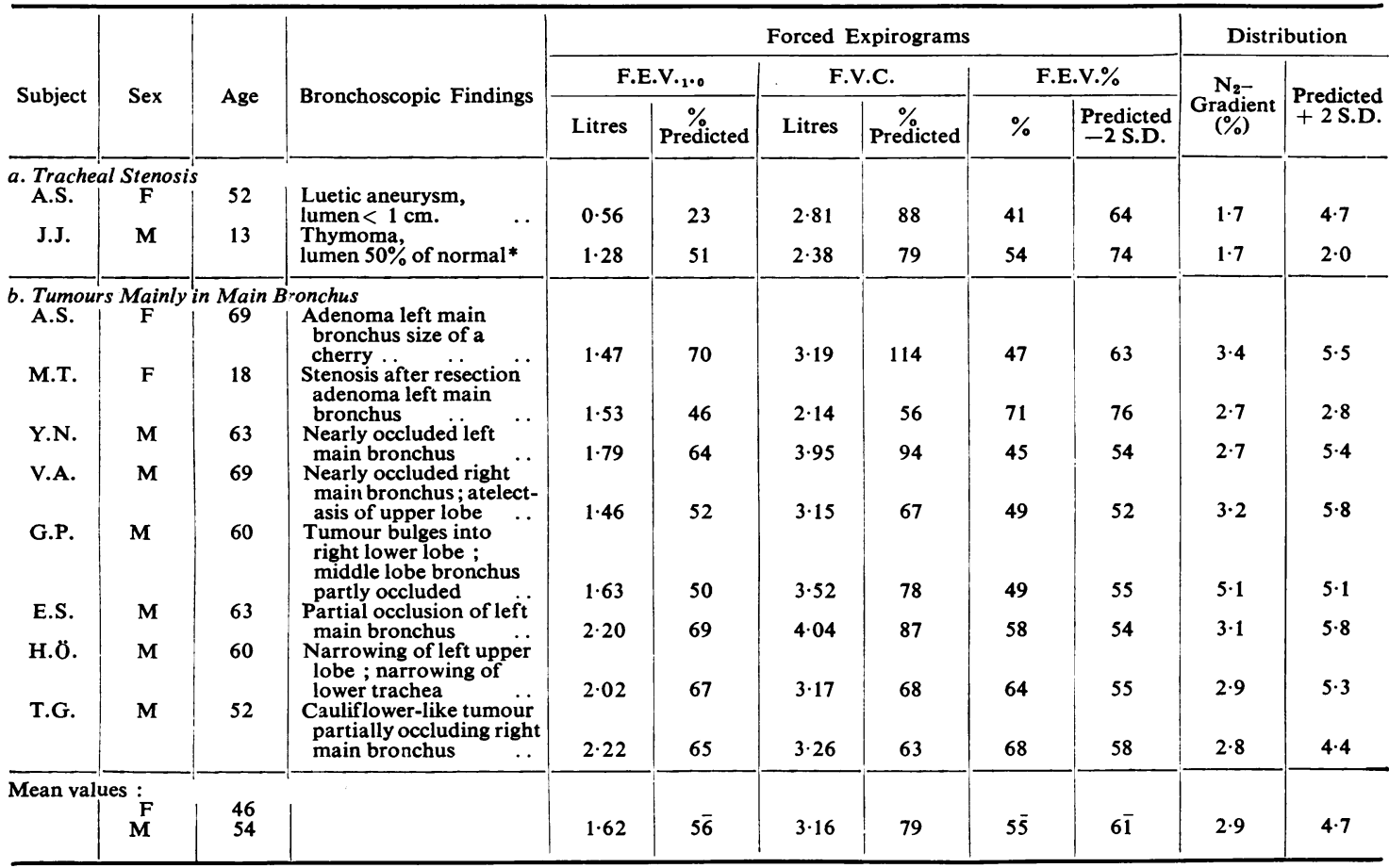

${ }^{*}$ F.I.V. ${ }_{1.0}=0.91 ;$ F.I.V.C. $=1.85 ;$ F.I.V. $\%=50$

In group 2, seven of nine subjects had an $\mathrm{N}_{2}-$ gradient higher than the upper $95 \%$ confidence limit. The difference between the predicted upper limit and the actual gradient was significant $(P<0.05)$. Five patients were obstructive; the remaining four were restrictive (Table II).

\section{DISCUSSION}

In most subjects with generalized airway obstruction the $\mathrm{N}_{2}$-gradient is large and the F.E.V.\% is low. In some cases with slight obstruction only, the $\mathrm{N}_{2}$-gradient is pathological (Malmberg, Simonsson, and Berglund, 1963).

In subjects with only localized obstruction, a pathological F.E.V. \% is often obtained together with a normal $\mathrm{N}_{2}$-gradient. The most extreme obstructive spirometric pattern is an amputation of the V.C. which creates the picture of a 'restrictive' ventilatory impairment. The tumour conceivably occludes the airway totally in some phase of the expiration, when the airway is compressed due to a fall in the intraluminal pressure behind the narrowing point. The V.C. thus might become more impeded than the F.E.V. ${ }_{\cdot 1,0}$ which renders the F.E.V. \% normal.

A narrowed central airway does not seem to create an obvious asynchronous emptying of the gas from the lungs. There are reasons to believe that a central obstruction might even make the emptying of peripheral parts more equal due to pressure dilatation of narrowed airways ( $c f$. 'pursed lips breathing').

In patients with widespread bronchitis or emphysema, different time constants throughout the lungs give an asynchronous emptying (Otis, McKerrow, Bartlett, Mead, McIlroy, Silverstone, and Radford, 1956). With the addition of a local tumour in the central airways, a large pre-existing $\mathrm{N}_{2}$-gradient still persists. The single-breath nitrogen test thus can be used to assess the nature of airway obstruction in patients with bronchial tumours. If there is a pathological $\mathbf{N}_{2}$-gradient, there is reason to assume the presence of generalized airways obstruction. 
TABLE II

VENTILATORY CAPACITIES AND GAS DISTRIBUTION IN THE LUNGS OF PATIENTS WITH BOTH BRONCHIAL TUMOUR AND CHRONIC RESPIRATORY DISEASE

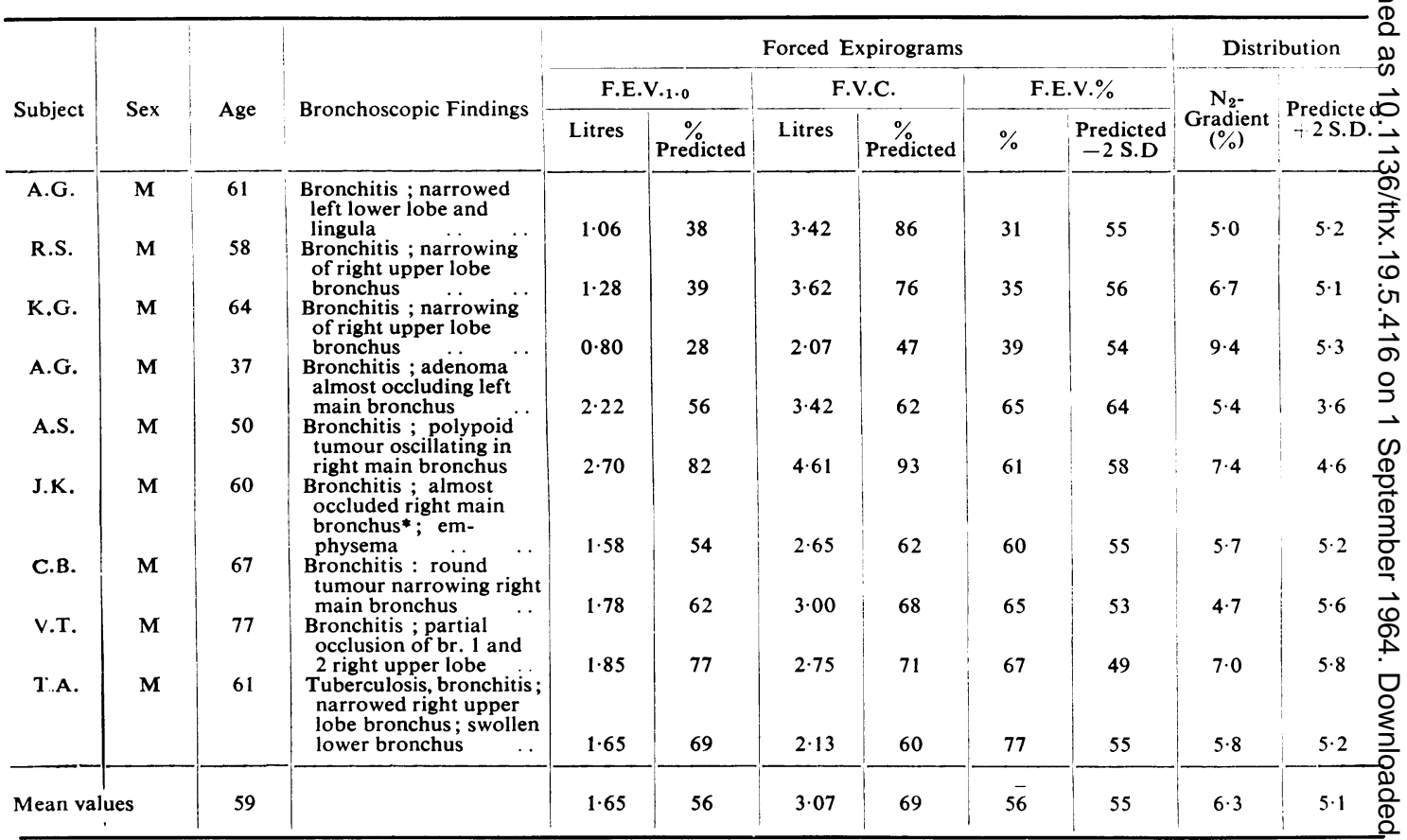

*Pathological anatomical diagnosis

TABLE III

VENTILATORY PARAMETERS AND DISTRIBUTION IN DIFFERENT BRONCHIAL CONDITIONS

\begin{tabular}{|c|c|c|c|c|c|c|c|}
\hline \multirow{2}{*}{ Bronchial Condition } & \multicolumn{3}{|c|}{ Forced Expirograms } & \multicolumn{3}{|c|}{ Forced Inspirograms } & \multirow{2}{*}{$\underset{\text { Gradient }}{\mathrm{N}_{2--}}$} \\
\hline & F.E.V.1.0 & F.V.C. & F.E.V. $\%$ & F.I.V.1.0 & F.I.V.C. & F.I.V.\% & \\
\hline Tracheal stenosis & Lowered & Lowered & Lowered & $\begin{array}{c}\text { Increased } \\
\text { F.E.V.> F.I.V. }\end{array}$ & Lowered & Lowered & Normal \\
\hline $\begin{array}{l}\text { Tumour in main } \\
\text { bronchus }\end{array}$ & Lowered & Lowered & $\begin{array}{l}\text { I.owered } \\
\text { (normal) }\end{array}$ & $\begin{array}{c}\text { Increased } \\
\text { F.I.V.> F.E.V. }\end{array}$ & Lowered & & Normal \\
\hline $\begin{array}{l}\text { Generalized airways } \\
\text { obstruction + central } \\
\text { tumour }\end{array}$ & Lowered & Lowered & Lowered & F.I.V.> F.E.V. & & & Pathologica \\
\hline
\end{tabular}

As a further means of differentiation between localized and generalized obstruction, bronchodilating drugs could be tried. Irreversibility of a short-lasting obstruction points to a localized hindrance to airflow.

\section{SUMMARY AND CONCLUSION}

Dynamic ventilatory capacities and the singlebreath nitrogen test of asynchronous pulmonary ventilation were compared in patients wittw bronchoscopically observed narrowing due to tracheal or bronchial tumours.

In two subjects with tracheal stenosis the्ष expiratory and inspiratory obstruction was severe, but the $\mathrm{N}_{2}$-test was still normal. In eight other patients without an earlier history of bronchitio or emphysema, the obstructive spirometry was noథ combined with a pathological distribution.

In nine patients with tumours and a history 
chronic bronchitis or emphysema, the obstructive or restrictive ventilatory capacity co-existed with definitely asynchronous gas distribution.

The $\mathrm{N}_{2}$-test combined with spirometry is of value in differentiating between generalized and localized airway obstruction.

\section{REFERENCES}

Bernstein, L., D'Silva, J. L., and Mendel, D. (1952). The effect of the rate of breathing on the maximum breathing capacity determined with a new spirometer. Thorax, 7, 255.

Berglund, E., Birath, G., Bjure, J., Grimby, G., Kjellmer, I., Sandqvist,
L., and Söderholm, B. (1963). Spirometric studies in normal subjects. I. Forced expirograms in subjects between 7 and 70 years of age. Acta med. scand., 183, 185.

Gandevia, B., and Hugh-Jones, P. (1957). Terminology for measurements of ventilatory capacity. Thorax, 12, 290.

Kjellmer, I., Sandqvist, L., and Berglund, E. (1959). "Alveolar plateau" of the single breath nitrogen elimination curve in normal subjects. J. appl. Physiol., 14, 105.

Malmberg, R., Simonsson, B., and Berglund, E. (1963). Airways obstruction and uneven gas distribution in the lung. Thorax, 18, 168.

Otis, A. B., McKerrow, C. B., Bartlett, R. A., Mead, J., McIlroy, M. B., Selverstone, N. J., and Radford, E. P. (1956). Mechanical factors in distribution of pulmonary ventilation. J. appl. Physiol., 8, 427.

Sandqvist, L., and Kjellmer, I. (1960). Normal values for the single breath nitrogen elimination test in different age groups. Scand. J. clin. Lab. Invest., 12, 131. 